\title{
Effect of Epidural Bupivacaine Versus Intrathecal Single Dose in Analgesia during Normal Vaginal Labor of Multiparous Women
}

\author{
AMIRA A. AWAD, M.D.*; GEHAN A. ELDESOKY, M.D.* and MONA A. ALKAFRAWY, M.D.** \\ The Department of Anesthesia \& Intensive Care* and Obstatric \& Gynecology Department**, Faculty of Medicine for Girls, \\ Al-Azhar University, Egypt
}

\begin{abstract}
Background: Epidural analgesic technique is the most commonly used and most effective analgesia during labor. Intrathecal labor analgesia is alternatively and effective method to provide labor analgesia.
\end{abstract}

Aim of Study: To compare the effect of epidural bupivacaine versus single-dose intrathecal bupivacaine during labor of multiparous women on the duration of labor analgesia, progress of labor, block characteristics and side effects.

Material and Methods: In a prospective randomized double-blind study, 80 multiparous women of ASA class I and II were randomly allocated into two groups of pregnant women 40 each. The spinal group received hyperbaric bupivacaine $0.5 \%$ at a dose of $3.75 \mathrm{mg}(0.75 \mathrm{ml})$ of hyperbaric bupivacaine with $25 \mathrm{ug}$ fentanyl $(0.5 \mathrm{ml})$ and diluted with sterilized normal saline to $1.5 \mathrm{ml}$ whereas the epidural group received isobaric bupivacaine $8-10 \mathrm{ml}$ of $0.125 \%$ bupivacaine with fentanyl 50g. Patients were monitored for hemodynamics, sensory and motor block characteristics, side effects, duration of stages of labor and pain intensity was also recorded on a visual analogue scale.

Results: Maternal hemodynamics showed a nonsignificant changes between both groups. Onset of sensory block and duration were significantly delayed in epidural group in comparison to spinal group $(8.80 \pm 5.27,163 \pm 16.64 \mathrm{~min})$ vs $(4.6 \pm 1.20,120.2 \pm 3.33 \mathrm{~min})$ and visual analogue scale comparable in both groups but scale was lower in the spinal group. Patient's satisfaction was insignificantly more in $\mathrm{S}$ group. The duration of the first and second stages of labor in the spinal group was shorter than that in the epidural group and incidence of maternal complications in both groups were insignificant.

Conclusion: A safe and effective alternative method to epidural analgesia is a single-dose intrathecal bupivacaine.

Key Words: Epidural analgesia-Intrathecal bupivacaineVaginaldelivery.

\section{Introduction}

LABOR is a physiologic process but associated with the severest form of pain. In 1979 the Inter-

Correspondence to: Dr. Amira A. Awad, The Department of Anesthesia \& Intensive Care, Faculty of Medicine for Girls, Al-Azhar University, Egypt national Association for the study of Pain defined pain as "an unpleasant sensory and emotional experience associated with actual or potential tissue damage, or described in terms of such damage". Pain has at least two components, sensory and affective (or emotional). Pain during labor and childbirth is a complex combination of physical and psychological factors (multidimensional response to sensory stimuli generated during childbirth). Pain comes from the uterus, cervix, pelvic joints, ligaments and from the vagina and perineum stretching to accommodate the baby's emerging body. But fear and tension make the pain much worse [1,2].

The use of analgesic techniques to relieve labor pain has become more frequent. Neuraxial analgesia is a popular technique to manage labor pain. Epidural, spinal anesthesia and combined spinalepidural anesthesia is considered the most effectivetechniques. Each one has its advantages and side effects on the mother and/or the fetus [3]. Epidural analgesia is the most commonly used technique for labor relief pain but has been associated with prolonged labor, the slow onset of action, increased chance of instrumental deliveries, debate of the increased incidence of C-sections. Spinal analgesia may be a useful alternative for relief labor pain. The use of single-low dose intrathecal bupivacaine for labor analgesia has been demonstrated and found to be effective [4]. The advantages of this form of technique are the rapidity of onset and reliability, easily performed with minimal hemodynamic changes, low doses, less motor block and more economical. Several adjuvants have been added to intrathecal bupivacaine to prolong the duration of sensory block such as fentanyl, morpine and dexmedetomidine $[\mathbf{5 , 6 ]}$.

In our study we investigate the analgesic effect of low dose spinal anesthesia and verified that low dose spinal anesthesia can be used instead of epidural 
analgesia and produce satisfactory results for the mother and the baby. The technique can effectively replace epidural analgesia during normal labor.

\section{Patients and Methods}

A prospective, randomized, comparative study was conducted on 80 multiparous parturient who received antenatal care, presenting for vaginal delivery and requesting analgesiain the Obstetric Department in Al-Zahra University Hospital, AlAzhar University, Cairo from December 2017 to December 2019. Informed consent was obtained from the parturient, using computer-generated in randomization (Random Allocation Software, M. Saghaei, Isfahan, Iran).

Patients included in the study were parturient with American Society of Anesthesiologists (ASA) physical status I and II, aged 18-45 years multiparous women, full term singleton pregnancy, cephalic presentation in the active stage of labor (cervical dilatation of $>$ - $4 \mathrm{~cm}$ ) and bishop scoring is more than 5 requesting [7]. For analgesia during labor. Exclusion criteria were patient with neuraxialanesthesia contraindication such as (coagulopathy, skin infection at the injection site, high intracranial pressure), allergy to opioids or local anesthetics, neurological disease, all complicated pregnanciessuch as (pregnancy induced hypertension, congenital fetal male formation, fetal male presentation like breech or transverse presentation, placenta previa, anomalies in the variety of fetal presentation) and morbid obesity.

Patients were randomly assigned into two groups contains 40 pregnant women in each (group E) received epidural analgesia and (group S) received intrathecal hyperbaric bupivacaine $0.5 \%$.

Preoperative assessment of the patients was carried out including complete detailed history, clinical examination, and basic investigations. In the preanesthetic room, an 18 gauge intravenous cannula was inserted and $10 \mathrm{ml} / \mathrm{kg}$ normal saline or ringers lactate as a preload or coload was started. Then The parturient connected to the monitor for baseline vital signs such as pulse rate, blood pressure (MAP), oxygen saturation and the fetal heart rate was checked with continues monitor (CTG), uterine contractions, cervical dilatation and bishop scoring were assessed by the attending obstetrician, baseline pain was also assessed using visual analog scale $(\mathrm{VAS})(0=$ No pain and $10=$ Severe pain $)$.

At an attainment of (cervical dilation $>44 \mathrm{~cm}$ and bishop scoring $>$ _5), analgesia was started with the patient in the sitting position or in left lateral position, using a completely aseptic technique and infiltration of the skin by $3 \mathrm{ml}$ lidocaine $2 \%$ at L34 or L4-5.

In group $S$, patients received spinal anesthesia which was performed using either 25 or $22 \mathrm{G}$ spinal needles (Quincke needle; Becton Dicknson, Spain). After confirmation of free flow of cerebrospinal fluid, $3.75 \mathrm{mg}(0.75 \mathrm{ml})$ of hyperbaric bupivacaine ( Marcaine 0.5\% Spinal Heavy, Astra Zeneca, CENEXI, France). With $25 \mathrm{ug}$ fentanyl $(0.5 \mathrm{ml})$ and diluted with sterilized normal saline to $1.5 \mathrm{ml}$ (total volume $1.5 \mathrm{ml}$ in one syring) were slowly injected via spinal needle. Rescue analgesia (if required for VAS >5) was administered in the form of injection ketamine $0.5-1 \mathrm{mg} / \mathrm{kg}$ body weight slow I.V. over $5 \mathrm{~min}$ and local lidocaine during episiotomy by obstetrician which was done after fully dilatation and engagement of fetal head if needed.

In group E, patients received epidural analgesia was performed by an 18-G Tuohyepidural needle ( Tuohy catheter, prefix set for continuousepidural anesthesia; B-Braun Medical Inc., Melsungen, Germany) was advanced slowly into the epidural space L3-L4 or L4-L5 intervertebral space using the loss of resistance to airtechnique. When feeling good loss of resistance, the epidural catheter was inserted $3-4 \mathrm{~cm}$ cephalad into the epidural space, fixed catheter with plaster, after negative aspiration for blood or spinal fluid a test dose of $3 \mathrm{ml}(60 \mathrm{mg})$ lidocaine $2 \%$ was given via inserted catheter. Five minutes after a test dose, parturient women receivedisobaric $0.5 \%$ bupivacaine $(20 \mathrm{ml}$ vial $0.5 \%$ Marcaine 0.5\%; Astra Zeneca, Sweden). The initial dose in epidural catheter is $8-10 \mathrm{ml}$ of $0.125 \%$ bupivacaine with fentanyl 50gg. If a patient requested again for analgesia, intermittent manual top ups doses of $6-8 \mathrm{~mL} 0.125 \%$ bupivacaine were given. Patients were immediately positioned in supine position, kept at 15 degrees left lateral tilt.

\section{The studied parameters were:}

1- The maternal hemodynamic (HR, MAP) from base line (before the beginning of drug administration) and then every 30 minutes until the birth. Bradycardia were treated with I.V. atropine $(5-10 \mathrm{~g} / \mathrm{kg}$ ) and maternal hypotension was defined as a fall in systolic blood pressure of more than $20 \%$ from the baseline and was treated by giving additional ringer lactate or injection of ephedrine intravenously.

2- Onset of sensory blockade (detected by pinprick test using 22 gauge blunt needle and define as the time from the intrathecal injection of the study drug till reach peak sensory dermatome level). 
3- Duration of sensory block (time from onset of block till first analgesia need, VAS $>4$ ).

4- The patient's pain was recorded by the visual analog scale (VAS) to assess maternal pain ( where $0=$ represent no pain and 10 represent worst pain) was done at baseline (cervix was $<4 \mathrm{~cm}$ ) from base line (before the beginning of drug administration) and then every 30 minutes until the birth.

5- The incidence of adverse effect including: Hypotension, bradycardia, nausea, vomiting, shivering, purities were also recorded.

6- Duration of first and second stage of labor, patient's satisfaction and complications.

Patients during labor under the direct supervision of the obstetrician for follow-up of the frequency and intensity of uterine contractions, dilation, and effacement of the cervix, descent of the presenting part and requirement of oxytocin (when cervical dilation rate was $<1 \mathrm{~cm} / \mathrm{h}$ ) were assessed using the standard partogram chart to plot the progress of cervical dilation hourly and uterine contraction per $10 \mathrm{~min}$. FHR was monitored using an electronic fetal monitor (CTG). Also the decision to proceed to operative delivery was made by the team according to maternal or fetal indications. If Poor progress of labor was diagnosed or there was requirement for caesarean section such parturient were excluded from the study.

The primary outcome of this study: Evaluation of the efficacy of analgesia and safety of intrathecal versus epidural analgesia with bupivacaine during normal delivery inmultiparous women. Secondary outcome was comparing the hemodynamic impact in the early phase of labor of intrathecal versus epidural route and duration of stages of labor.

\section{Sample size justification:}

MedCalc® version 12.3.0.0 program "Ostend, Belgium" was used for calculations of sample size, statistical calculator based on $95 \%$ confidence interval and power of the study $80 \%$ with $\alpha$ error $5 \%$, According to a previous study Abd El Barr et al. [8] showed that the mean of Pain Score at $120 \mathrm{~min}$. in group $\mathrm{S}(3.8 \pm 1.03)$ Compared to $\mathrm{E}$ (6.7 \pm 2.1$)$, with mean difference 2.9 and $p$-value $<0.001$. So it can be relied upon in this study, based on this assumption, sample size was calculated according to these values produced a minimal samples size of 80 cases were enough to find such a difference, subdivided into two groups; Group $E(n=40)$ and Group $S(n=40)$.

\section{Statistical analysis:}

Data were statistically described in terms of mean and standard deviation (SD) and range of frequencies (number of cases) and percentages when appropriate. A comparison of numerical variables between the study groups was done using the Student's $t$-test for independent samples with parametric distribution. For comparing categorical data, chi-square test was performed. $p$-values less than 0.05 were considered statistically significant. All statistical calculations were done using computer program IBM SPSS (Statistical Package for the Social Science; IBM Corp, Armonk, NY, USA) version 22 for Microsoft Windows.

\section{Results}

There was no statistically significant difference between both groups regardingage, ASA, weight, height, gestation age (Table 1).

Table (1): Demographic data in both groups.

\begin{tabular}{lccccc}
\hline Parameter & $\begin{array}{c}\text { E group } \\
(\mathrm{n}=40)\end{array}$ & $\begin{array}{c}\text { S group } \\
(\mathrm{n}=40)\end{array}$ & $\begin{array}{c}\text { Test } \\
\text { value }\end{array}$ & $\begin{array}{c}p- \\
\text { value }\end{array}$ & Sig. \\
\hline Age (yr) & $28.06 \pm 7.22$ & $29.03 \pm 8.61$ & 0.546 & 0.587 & NS \\
ASA class\#: & & & & & \\
$\quad$ I & $28(52.0 \%)$ & $21(56.0 \%)$ & & & \\
II & $12(48.0 \%)$ & $19(44.0 \%)$ & 1.896 & 0.169 & NS \\
Weight (kg) & $78.11 \pm 5.51$ & $79.50 \pm 6.47$ & 1.034 & 0.304 & NS \\
Height (cm) & $160.65 \pm 6.57$ & $158.86 \pm 7.12$ & 1.169 & 0.246 & NS \\
$\begin{array}{c}\text { Gestation age } \\
\text { (week) }\end{array}$ & $39.62 \pm 1.68$ & $39.13 \pm 1.80$ & 1.259 & 0.212 & NS \\
\hline
\end{tabular}

*Using: Independent Sample $t$-test. \#Chi-square test.

According to heart rate: There was no statistically significant difference in heart rate between both groups but there was decrease in HR in the $\mathrm{S}$ group in comparison to $\mathrm{E}$ group except at $90 \mathrm{~min}$ ( $p$-value >0.05) (Fig. 1).

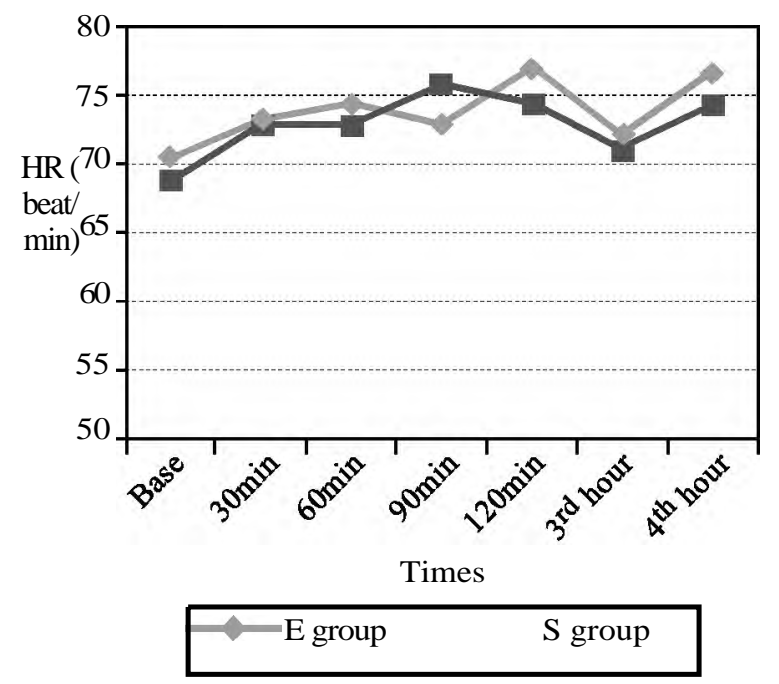

Fig. (1): Comparison between both groups regarding HR. 
According to Mean Arterial Blood Pressure ( $M A P)$ : There was no statistically difference in MAP between both groups but there was slight decrease in MAP insignificantly in the $S$ group in comparison to $\mathrm{E}$ group at all study times ( $p$-value $>0.05$ ) as shown in (Fig. 2).

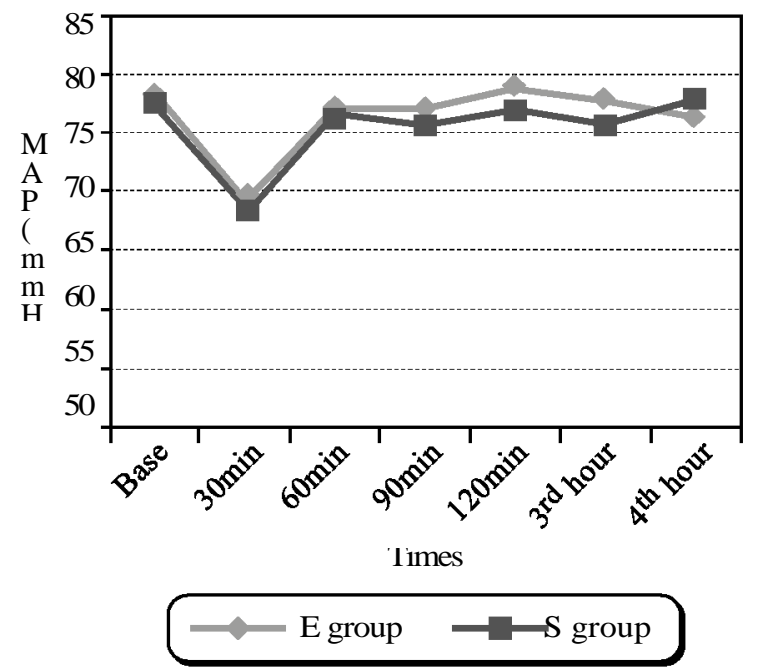

Fig. (2): Comparison between both groups regarding

Onset of sensory block was significantly delayed in epidural group when compared to intrathecal group and duration sensory of blockade was significantly prolonged in epidural group in comparison to intrathecal group (Table 2 and Fig. 3).

Table (2): Sensory onset and duration in both groups.

\begin{tabular}{|c|c|c|c|c|c|}
\hline & $\begin{array}{c}\text { E group } \\
(n=40)\end{array}$ & $\begin{array}{l}\text { S group } \\
(\mathrm{n}=40)\end{array}$ & $\begin{array}{c}\text { Test } \\
\text { value }\end{array}$ & $\begin{array}{c}p- \\
\text { value }\end{array}$ & Sig. \\
\hline $\begin{array}{l}\text { Onset of sensory } \\
\text { block (min) }\end{array}$ & ర్గ. & $4.0 \pm 1$ & 4.910 & $<U .001$ & HS \\
\hline $\begin{array}{l}\text { Duration of } \\
\text { sensory } \\
\text { block (min) }\end{array}$ & $163 \pm 10$. & $120.2 \pm 23$. & 15.951 & $<0.001$ & HS \\
\hline
\end{tabular}

Using: Independent sample test.

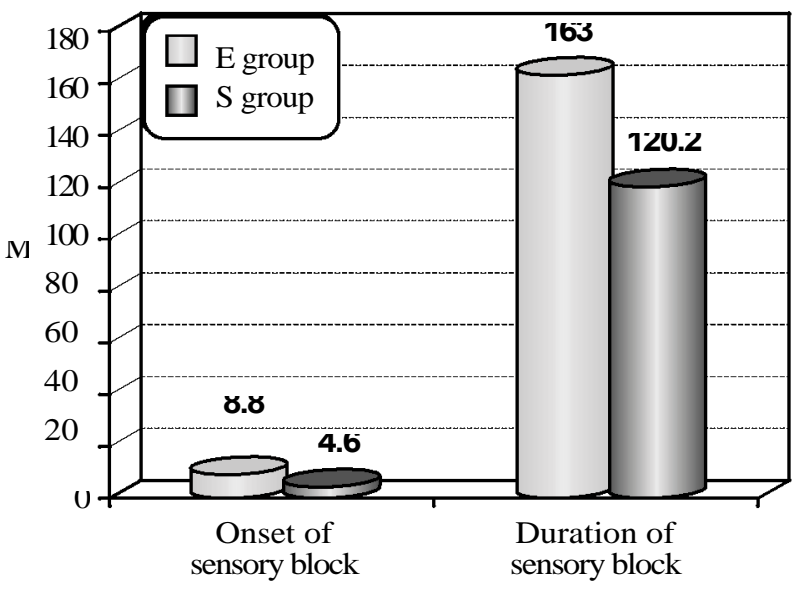

Fig. (3): Sensory onset and duration in both
Multiparous women receiving epidural analgesia had insignificantly higher mean pain scores than spinal group for the first and the second stages of labor (the VAS scores were comparable in both groups at all time intervals of the study) (Fig. 4).

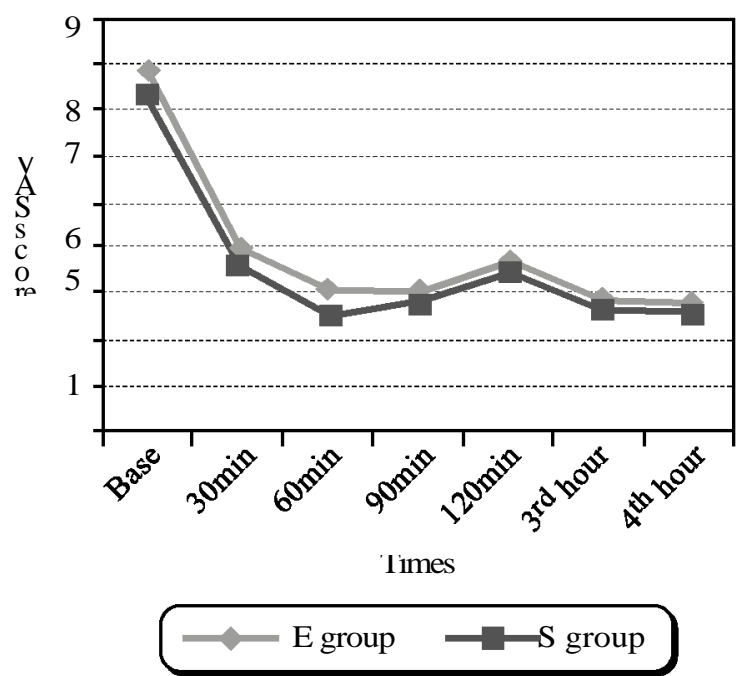

Fig. (4): Comparison of VAS scores between both groups.

An epidural top dose as a rescue analgesic was needed by twelve parturient in group E (30\%). On the contrary, in group $S$ ten parturient $(25 \%)$ needed local analgesia of lidocaine for episiotomy by obstetrician. Although women in both groups expressed overall satisfaction with pain management duringlabor, there were insignificant differences between groups but women in spinal group were more satisfied than women in epidural group $(90 \%$ versus $85 \%$ ) levels of satisfaction correlated with lower overall VAS scores during labor (Fig. 5).

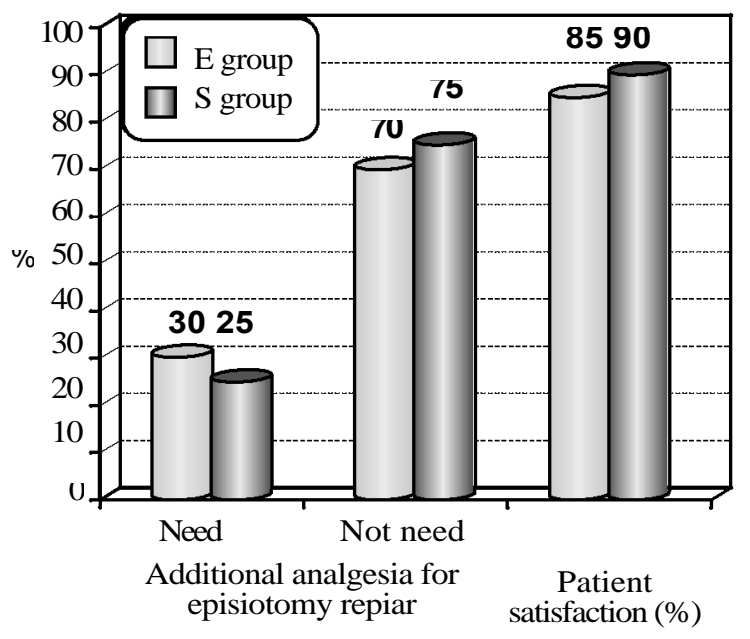

Fig. (5): Additional analgesia for episiotomy repair and Patient satisfaction in both groups. 
Duration of the first stage of labor, in the epidural group had significantly less cervical dilation time $(130.18 \pm 5.27 \mathrm{~min})$ in comparison to spinal group $(123.0 \pm 20.2 \mathrm{~min})$. Also in spinal group, the duration of the second stage of labor had successful less duration than women receiving epidural analgesia $(12.02 \pm 1.37 \mathrm{~min}$ versus $22 \pm 16.64 \mathrm{~min})$. The maternal complications like instrumental delivery and post-partum hemorrhage were comparable between both groups (Table 3 ).

Table (3): Stages of labor and maternal complications.

\begin{tabular}{|c|c|c|c|c|c|c|}
\hline & $\begin{array}{c}\text { E group } \\
(n=40)\end{array}$ & & $\begin{array}{l}\text { S group } \\
(n=40)\end{array}$ & $\begin{array}{c}\text { Test } \\
\text { value }\end{array}$ & $\begin{array}{c}p- \\
\text { value }\end{array}$ & Sig. \\
\hline $\begin{array}{r}\text { Duration of first } \\
\text { stage of labor }\end{array}$ & $\begin{array}{l}130.18 \pm 5 . \\
27\end{array}$ & & $\begin{array}{r}23.0 \pm 20 \text {. } \\
2\end{array}$ & 4.915 & $<0.001$ & HS \\
\hline $\begin{array}{c}\text { Duration of } 2 \mathrm{nd} \\
\text { stage }(\mathrm{min})\end{array}$ & $22 \pm 16.64$ & & $\begin{array}{r}12.02 \pm 1 \\
37\end{array}$ & 15.951 & $<0.001$ & HS \\
\hline \multicolumn{7}{|l|}{$\begin{array}{l}\text { Maternal } \\
\text { complications: }\end{array}$} \\
\hline $\begin{array}{l}\text { Instrumental } \\
\text { delivery }\end{array}$ & $2(0.8 \%)$ & 1 & $(0.4 \%)$ & 0.342 & 0.595 & NS \\
\hline $\begin{array}{l}\text { Post-partum } \\
\text { hemorrhage }\end{array}$ & $2 \quad(0.8 \%)$ & 1 & $(0.4 \%)$ & 0.342 & 0.595 & NS \\
\hline
\end{tabular}

Using: Chi-square test and Independent sample test.

According to side effects: There was no statistically difference in both groups ( $p$-value $>0.05$ ) as regarding side effects but women receiving epidural analgesia were insignificantly less likely to experienced nausea, vomiting, bradycardia, shivering and hypotension) than women received spinal analgesia however, no women in the study experience pruritus in both groups (Fig. 6).

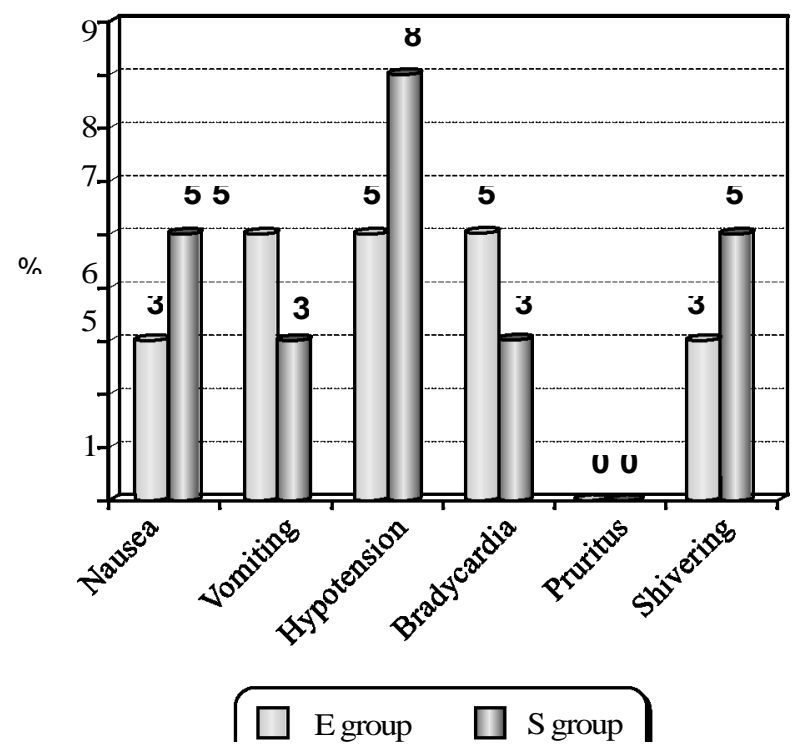

Fig. (6): Comparison of both groups as regard side effects.

\section{Discussion}

Neuraxial analgesia is a popular technique to manage labor pain and has being considered as the gold standard in obtaining maternal pain relief during labor. It can be done in three different ways: Epidural, spinal andcombining epidural-spinal [9]. The objectives of the present study were to compare analgesic effects and durationplus hemodynamic changes of epidural versus spinal during labor analgesia in multiparous women.

As regarding maternal hemodynamic changes ( HR and MAP) in the current study no significant changes between both groups. In agreement with the present study Rabiei et al. [10] conducted their study to compare the effects of epidural and spinal on the analgesia and blood gases in neonates born during vaginal delivery and revealed that the hemodynamic status of the mothers before and during the first postoperative period was in the normal range. In the same line of our study Meneghetti et al. [11] who compared hemodynamic impact of intrathecal versus epidural analgesia with sufentanilin parturient in first stage of labor. Also, cochrane review [12] that compared CSEA (Combined spinal epidural analgesia) and EA (epidural analgesia) involving 3274 women found no difference in maternal hypotension whereas a more rapid onset of analgesia in the CSEA. This finding agrees with the study done by El-Kerdawy and Farouk [ 13], who proved that both, parturient receiving epidural alone and parturient receiving remifentanil intravenous patient-controlled analgesia alone, were comparable with respect to maternal hemodynamics in terms of systolic blood pressure and HR. In contrast to the current study, Van der Vyveret al. [14] demonstrated that maternal hypotension occurred in less than $3 \%$ of cases in their study comparing epidural bupivacaine patient-controlled analgesia with epidural bupivacaine continuous infusion for labor analgesia.

In the current study, as regarding the onset time of sensory was early in intrathecal group than epidural group and duration of sensory block was prolonged in $\mathrm{S}$ group than $\mathrm{E}$ group. Visual analogue scores during all time study were lower in $\mathrm{S}$ group compared to E group but without significant changes. Similar to our results, Younes et al. [15] who compared two groups, the spinal group received hyperbaric bupivacaine $0.5 \%$ at a dose of $1 \mathrm{ml}$ plus $25 \mathrm{~g}$ fentanyl $(0.5 \mathrm{ml})$, whereas the epidural group received bupivacaine $0.25 \%$ at a $14 \mathrm{ml}$ bolus dose, the onset of sensory block in spinal was earlier than epidural group $(5.6 \pm 1.27$ vs. $8.8 \pm 1$. $62 \mathrm{~min}, p<0.001)$ Against to our results as regard significant 
concept, Abdelbarr et al. [8] compared two groupsone group received intrathecal $3.75 \mathrm{mg}$ hyperbaric bupivacaine and the other group received $4 \mathrm{ml}$ bupivacaine with $4 \mathrm{ml}$ saline and found that onset of sensory block was early $(4.4 \pm 1.5 \mathrm{~min}$ vs 12.5 $\pm 2.3 \mathrm{~min})$ and duration of sensory block was longer ( $120.4 \pm 15.6$ vs $103.2 \pm 18.3 \mathrm{~min}$ ) in $\mathrm{S}$ group compared to $\mathrm{E}$ group. Visual analogue scores after 5, $15,30,60,90,120$ and 150min were lower in $\mathrm{S}$ group compared to E group, all the previous result is statically significant $(p<0.001)$.

Coincides with our results Minty RG et al. [16] who examinedthe safety and efficacy of single dose spinal analgesia during labor. Medline was searched and the references of 2 systematic reviews and a meta-analysis were reviewed to find articles on obstetric analgesia and pain measurement. The literature supports use of spinal anesthesia as a safe and effective alternative to epidural anesthesia; they concluded that single-dose spinal.

As regarding side effects of analgesia during labor, there was no statistically difference in both groups.

Similar to our results ,Younes et al. [15] they compared the same two groups of our study and found that the duration of the first and second stages of labor in the spinal group was shorter than that in the epidural group. $90 \%$ of parturient in the spinal group versus $60 \%$ in the epidural group were satisfied by the analgesic quality. But this study in contrast to our study because the incidences of nausea and vomiting were highest in the epidural group than in the spinal group with nonsignificant difference between them, whereas pruritus was significantly higher in the spinal group compared with the epidural group $(p<0.05)$. In contrast to the current study, Many researches proved that intrathecal opioid injections were associated with a greater incidence of pruritus like Bucklin et al. [ 17] using single-injection intrathecal opioids versus epidural local anesthetics in labor analgesia.

Fontaine et al. [18] in another study, reported that intrathecal opioids were associated with significantly higher pain scores compared with epidural analgesia during the first and second stages of labor.

Krzysztof and Susilo Chandra [19] assess maternal satisfaction with single-dose spinal analgesia for the management of obstetric pain in Indonesian women. The investigation included 62 laboring women received single-dose spinal anesthesia with a combination of bupivacaine, $2.5 \mathrm{mg}$; morphine, 0 . $25 \mathrm{mg}$; and clonidine. The overall maternal satis faction with the single-dose spinal technique for labor analgesia in their study group was high, with 50 patients $(81 \%)$ being very satisfied, and 7 patients $(11 \%)$ being satisfied with the quality of labor analgesia.

The duration of first and second stages of labor were noted and complication of maternal delivery. On comparing our study with other studies on intrathecal labor analgesia, the mean duration of first stage of labor in the present study (123.0土 $20.2 \mathrm{~min}$ ) was relatively shorter as compared to the study done by Owen et al. [20] (171 $\pm 17.2 \mathrm{~min})$ and comparable to study of Mathur et al. [21] the mean duration was $(115.50 \pm 27.33 \mathrm{~min})$. Also, the duration of second stage of labor in current study was $12.02 \pm 1.37 \mathrm{~min}$ which consistent with the study conducted by Viitanen et al. [22] the duration of second stage was $9.6 \pm 10.7 \mathrm{~min}$. The instrumental vaginal delivery and Post-partum hemorrhage incidence had no statistically significant difference found between both groups, and in agreement to our study was study of Chauhan et al. [23].

\section{Conclusion:}

During vaginal delivery of multiparous women, use of single dose spinal analgesia is an effective alternative method to epidural analgesia in relieve labor pain in addition to spinal analgesia is low cost, fast and safe technique with less side effect.

\section{Conflicts of interest:}

There are no conflicts of interest.

\section{Funding:}

The research did not receive funding of any kind from either the government or non-government organizations.

\section{References}

1- ANIM-SOMUAH M., SMYTH R.M. and JONES L. Epidural versus nonepidural or no analgesia in labour. Cochrane Database Syst. Rev., 12, 2011.

2- American Society of Anesthesiologists Task Force on Obstetric: A. Practice guidelines for obstetric anesthesia: An updated report by the American Society of Anesthesiologists Task Force on Obstetric Anesthesia. Anesthesiology. Apr., 106 (4): 843-63, 2007.

3- O. ADEYEMI, R. VERNON and O. MEDGE: A spinal labour analgesia protocol for Ghana", in Proceedings of the 4th All Africa Anaesthesia Congress, pp. 67-68, 2009.

4- SCHNITTGER T.: Regional anesthesia in developing countries Anesthesia, 2007.

5- HESS P.E., PRATT S.D., SONI A.K., SARNA M.C. and ORIOL N.E.: An association between severe labor pain and cesarean delivery. Anesth. Analg., 90 (4): 881-886, nกnก 
6- MAKWANA J.C., SHIVRAJ T.N., KHADE A., BANSAL S., MANDAL N., GOSWAMI S. and BHARAT SHAH: Comparison between hyperbaric bupivacaine and hyperbaric bupivacaine plus fentanyl intrathecally in major gynecological surgeries. Int. J. Med. Sci. Public Health, 3: 319-323, 2014.

7- NCBI Bookshelf. A service of the National Library of Medicine, National Institutes of Health. Stat Pearls [Internet]. Treasure Island (FL): Stat Pearls Publishing, 2020.

8- ABD EL BARR T., ELSHALAKANY N.A. and SHAFIK Y. M.: Single dose spinal analgesia: Is it a good alternative to epidural analgesia in controlling labour pain? Egyptian Journal of Anaesthesia, 30: 241-246, 2014.

9- MILLER R., ERIKSSON L., FLIESHER L. and WINERKRONISH J.P.: Miller's anesthesia. 6ed. New York: McGraw-Hill, 2005.

10- RABIEI S., HAJIAN P., PIRDEHGHAN A., MABODI K. and KHANSARI S.: Comparison of the effects of epidural and spinal anesthesia on analgesia and blood gases in neonates born by natural vaginal delivery: A clinical trial study". Biomedical Research and Therapy, 7.3: 3686-3692, 2020.

11- MENEGHETTI G., GALLARDO A.R., RIPA C., VIARENGO V., FRACON S., FERRANTE D. and DELLA CORTE F.: Hemodynamic Impact of Intrathecal versus Epidural Analgesia with Sufentanil in the Early Phase of Labor: A Randomized Controlled Trial, 2017.

12- SIMMONS S.W., TAGHIZADEH N., DENNIS A.T., HUGHES D. and CYNA A.M.: Combined spinal-epidural versus epidural analgesia in labour. Cochrane Database Syst. Rev., 2012.

13- EL-KERDAWY H. and Farouk A.: Labor analgesia in preeclampsia: Remifentanil patient controlled intravenous analgesia versus epidural analgesia. Middle East J. Anaesthesiol., 20539-545, 2010.

14- VAN DER VYVER M., HALPERN S. and JOSEPH G.: Patient-controlled epidural analgesia versus continuous infusion for labour analgesia: A meta-analysis. Br. J.
15- YOUNESA M., GAMILB K. and ELGARHYA M.A.: Intrathecal hyperbaric bupivacaine with fentanyl for labor pain control: A comparative study with continuous epidural analgesia with bupivacaine. Ain-Shams Journal of Anaesthesiology, 10 (1): 230-236, 2017.

16- MINTY R.G., KELLY L., MINTY A. and D.C. HAMMETT: Single-dose intrathecal analgesia to control labour pain: Is it a useful alternative to epidural analgesia?". Canadian Family Physician, 53, No. 3: 437-442, 2007.

17- BUCKLIN B.A., CHESTNUT D.H. and HAWKINS J.L.: Intrathecal opioids versus epidurallocal anesthetics for labor analgesia: A meta-analysis. Reg. Anesth. Pain Med., 2723: 30, 2002.

18- FONTAINE P., ADAM P. and SVENDSEN K.H.: Should intrathecal narcotics be usedas a sole labor analgesic? A prospective comparison of spinal opioids and epidural bupivacaine. J. Fam Pract., 51: 630-635, 2002.

19- KRZYSZTOF M. and SUSILO CHANDRA: Maternal satisfaction with single dose spinal analgesia for labor pain in Indonesia: A landmark study. J. Anesth., 22 (1): 55-8, 2008.

20- OWEN M.D., OZSARAC O., SAHUN S., UCKUNKAYA N., KAPLAN N. and MAGUNACI I.: Low dose clonidine and neostigmine prolog the duration of intrathecal bupivacaine-fentanyl for labor analgesia. Anesthesiology, 92 (2): 361-366, 2000.

21- MATHUR P., JAIN N., PRAJAPAT L., JAIN K., GARG D. and KHANDELWAL V.: Effect of intrathecal analgesia using fentanyl and bupivacaine on progress of labor. J. Obstet. Anaesth. Crit. Care, 7: 47-51, 2017.

22- VIITANEN H., VIITANEN M. and HEIKKILA M.: Single-shot spinal block for labor analgesia in multiparous parturients. Acta. Anaesthesiol. Scand, 49 (7): 1023-1029, 2005.

23- CHAUHAN G., SAMYA P. and PATHANIA A.A.: Singledose intrathecal analgesia: A safe and effective method of labor analgesia for parturients in low resource areas, Ain-Shams Journal of Anesthesiology, 12: 23, 2020. 


\section{مقارنة تأ ثيرحقن البيوبافكين فى فوق الجافية الهافية

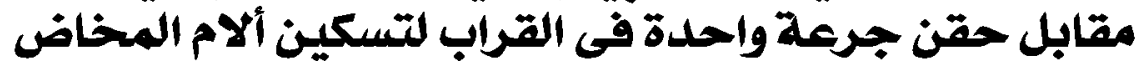

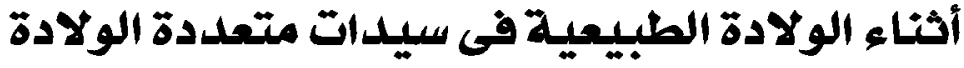

الخلفية: استخدام تقنية تسكين فوق الجافية هي الاكثر استخداماً وفاعلية في المسكنات أثثاء المخاض . ولقد أصبح تسكين داخل القراب بديلاً لتلك الطريقة وأكثر فاعلية في تسكين ألام المخاض. الهدف من الدراسة: لمقارنة تأ ثير بيوبافكين فوق الجافية مقابل جرعة واحدة داخل القراب خلال المخاض في النساء متعددة الولادة

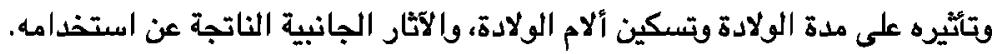

المواد والآساليب: هذه دراسة مزدوجة التعمية العشوائية المحتملة، تم تخصيص .A امرأة حامل متعددة الحمل من الفئة الأولى والثانية

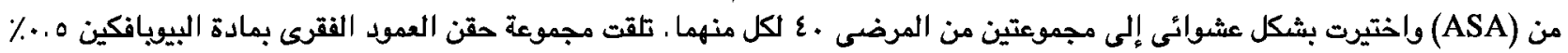

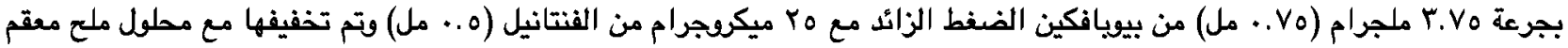

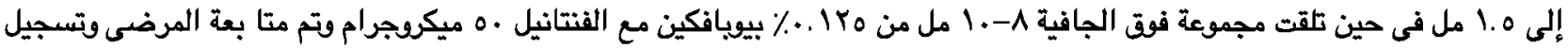

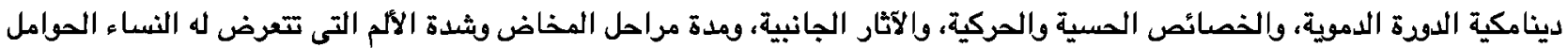
وتم تسجيلها أيضاً على مقياس التناظرية النهاية البصرية.

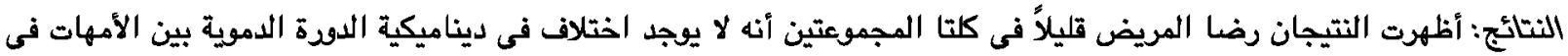

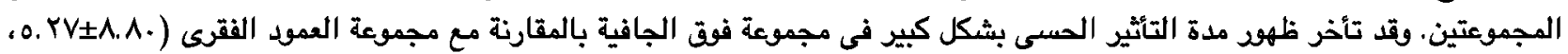

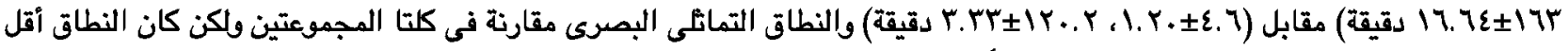

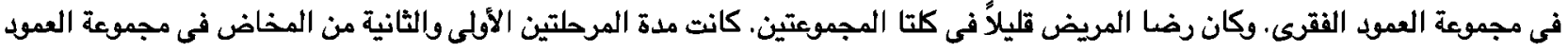

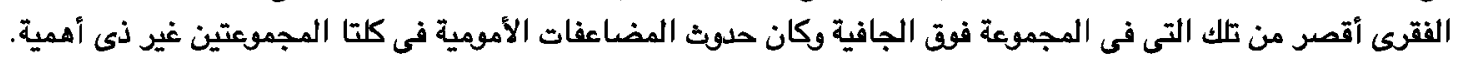
الخلاصة: جرعة واحدة داخل القراب بمادة البيوبافكين هي الطريقة البديلة الآمثة والفعالة لتسكين ألام المخاض من التسكين فوق الجافية. 